\title{
ERRATUM
}

\section{A comparative study on the immunotherapeutic efficacy of recombinant Semliki Forest virus and adenovirus vector systems in a murine model for cervical cancer}

A Riezebos-Brilman, M Walczak, J Regts, MG Rots, G Kamps, B Dontje, HY Haisma, J Wilschut and T Daemen

Gene Therapy (2008) 15, 66; doi:10.1038/sj.gt.3303084

Correction to: Gene Therapy (2007) 14, 1695-1704. doi:10.1038/sj.gt.3303036

Owing to a typesetting error, the second initial of one of the co-authors was corrected wrongly. The correct spelling is HJ Haisma.
The publisher apologizes for this error and any inconvenience it may have caused. 